Doing equality and difference : Representation and alignment in Finnish identification

\title{
Menard, Rusten
}

2016-11

Menard, R 2016 , ' Doing equality and difference : Representation and alignment in Finnish

pÿidentification ' , Text \& Talk , vol. 36 , no. 6 , pp. 733755 . https://doi.org/10.1515/text-2016-0032

http://hdl.handle.net/10138/236249

https://doi.org/10.1515/text-2016-0032

publishedVersion

Downloaded from Helda, University of Helsinki institutional repository.

This is an electronic reprint of the original article.

This reprint may differ from the original in pagination and typographic detail.

Please cite the original version. 


\title{
Rusten Menard*
}

\section{Doing equality and difference: Representation and alignment in Finnish identification}

DOI 10.1515/text-2016-0032

\begin{abstract}
Using tools from critical discourse analytic approaches informed by systemic functional linguistics, this paper is an examination of how social values - specifically equality values in Finland - are given meaning by differently socially positioned Finnish citizens, and how those meanings are positioned in constructions of identities. The focus of my examination is on how respondents align with different meanings of equality using linguistic resources of engagement and graduation (James R. Martin and Peter R. R. White [2005], The language of evaluation. Hampshire: Palgrave Macmillan). I conduct my analyses on written texts that were elicited in response to open items on a questionnaire. Respondents include individuals recruited through a national random sample, and individuals with transgendered life experiences and/or Asperger's diagnoses. I consider how being positioned in the margins by institutionalized norms may interact with representation and alignment of Finnish equality in identification. I also pay attention to how individuals strategically reconcile meanings of equality with other important yet potentially conflicting values, such as national identity, sameness and moderation. I discuss the implications of the study in relation to the historical path of equality, and in terms of how particular formulations of equality may contribute to building and maintaining relations of domination.
\end{abstract}

Keywords: social values, appraisal, resistance discourse, new racism, identity, positioning

\section{Introduction}

Although values are presumed integral to building ideologies in critical discourse studies, most critical discourse analytic researchers seem to take the concept of value and value meanings for granted (Sowińska 2013). Using tools

*Corresponding author: Rusten Menard, Unioninkatu 37, University of Helsinki, Department of Social Research, Social Psychology, 00014 Helsinki, Finland, E-mail: rusten.menard@helsinki.fi 
from critical discourse analysis informed by systemic functional linguistics, my objective in this paper is to examine the dynamics concerning how differently positioned Finnish citizens imbue social values of equality with meaning through classifications and demarcations of difference between who "we" are and who "they" are on the one hand (representation), and how they align with those classifications and representations on the other (identification). I understand social values as collectively generated, culturally embedded classification systems on desirability and acceptability that are used to construct "always becoming" identities and to define social orders (Menard 2016).

As with other Nordic countries, equality values in Finland are central to identification and social ordering (e. g. Kuusi 1964; Esping-Andersen 1990: 25). Although research on Finnish equality is vast and interdisciplinary, knowledge on lay understandings and uses of equality is lacking, particularly from a critical perspective. Additionally, the significance of how Finnish equality has developed alongside other important national projects has been underemphasized. My aims in this study are to attend to these lacks. I pay attention to how individuals strategically reconcile meanings of equality with other important yet potentially conflicting values. Unravelling representations and implementations of Finnish equality is important. Future forms of equality and the social orderings defined by those forms are impacted by their historical paths, the networks of socioculturally embedded classifications that are referenced to reconstitute their meanings, and how individuals position those networks in representing such meanings.

I work toward my objectives from a methodological standpoint by firstly analyzing respondents' "us" and "them" classifications in relation to equality. The focus of my examination is on respondents' alignments with equality representations using linguistic resources of ENGAGEMENT and GRADUATION (Martin and White 2005). These resources allow speakers and writers to build solidarity and distance with previous viewpoints around the same issue, as well as with individuals and groups believed to be sharing them. They provide a means for negotiating communities of shared values. In this study I also consider how these communities of shared values - which can also be understood as situational, cultural and social identities (see Törrönen 2014) - interact with structures of social class.

The paper proceeds as follows. I characterize my perspective on social values in Section 1.1. In Section 1.2, I situate the empirical study from a historical cultural standpoint. Methods are outlined in Sections 2-2.2. Sections 3-3.4 includes presentations of the discourses on equality that I identified from the entire corpus of texts. In these sections I also undertake close readings of how respondents use linguistic resources of ENGAGEMENT and GRADUATION to position and 
align with those equality discourses. In Section 4, I discuss the findings in relation to the historical path of equality. I also consider how particular formulations of equality may contribute to the building and maintenance of relations of domination; how they may contract human well-being and capabilities (see Fairclough and Fairclough 2012: 79-81).

\subsection{A critical dialogic perspective on social values}

Dialogic approaches to discourse view each utterance in the living social process as having an evaluative orientation and value judgments as being integral to the construction of meaning (Voloshinov 1986: 105). Social stratifications are stratifications of language, where different points of view are characterized by their own particular meanings and values (Bakhtin 1981: 291-292). I take as a starting point that value meanings are formulated out of human experiences and through different points of view (Tsirogianni and Sammut 2014). I also assume that meanings of social values encompass previous meanings and culturally specific discourses, yet are endlessly undergoing reformulation as actors implement those meanings in constructions of identity (see Menard 2016). Values are constituted in power-imbalanced social relations that they are continuously updating. They therefore both reflect and are used to define social orders.

I approach identification as temporary alignments with available subject positions and as never complete, rather than as examples of "essential" or “stable" identities (e. g. Hall 1990). Identities are formulated by actors in discursive events that involve both representations of social phenomenon through categorization and the building of storylines, and interpersonal positioning of oneself and others in relation to those categories and storylines (Davies and Harré 1990; Törrönen 2014). One way to approach empirical analyses of social values is to examine the dynamics concerning how individuals imbue values with meaning, and how they evaluate and position those meanings in identification.

\subsection{The historical path of Finnish equality}

The status and character of Finnish equality stems partially from its centrality in strong peasant traditions (Mäkelä 1985; Lempiäinen 2002). At least until the 1960s, the peasantry and rural classes were central symbols and actors in building Finnish national identity (Räsänen 1989; Häkli 1999). Equality in the 
form of anti-elitism and equal opportunities was of central importance (Granberg and Nikula 1995). Comprising the bulk of the membership in the temperance movement, the rural classes also valued moderation and selfcontrol (Alasuutari 1991). The temperance movement peaked at the turn of the twentieth century (Sulkunen and Alapuro 1987), the period in which the peasantry was also gaining political power. Their primary values of work, moderation, citizenship and equity were integral to nationalist ideologies (Granberg and Nikula 1995).

After Finnish independence (1917) and the Finnish Civil War (1918), a nationbuilding project included socializing efforts aimed at producing a unified image of Finland (Häkli 1999). Linguistic, sociocultural and ethnic differences came to be seen as a threat to the nationalist project, and were downplayed (Paasi 1992). The result was the production of a myth of Finland as an ethnically homogenous nation (Häkkinen and Tervonen 2004). After the Second World War, the political focus was on improving the standard of living and reducing class distinctions. The social policies of the welfare state aimed at offering all citizens the same provisions, supporting the traditional family unit and achieving equal participation of the sexes in the labor force.

While Finland has undergone drastic social restructuring and is not the same peasant society it once was, updated forms of values important to the peasantry still circulate in Finnish society. Some of these seem to be social problems. Granberg and Nikula (1995) suggest that the equality values of the peasantry have been reformulated in denial of the existence of social classes, while social differentiation is perceived as a threat to Finnish equality. The project on gender equality is often considered advanced and inherent to the Finnish nation (Holli 2003), while normative discourses on gender equality contract the space for diversity of practices (Julkunen 2002: 92; Tuori 2007).

Despite immigration rates in Finland being much lower than in other Nordic countries, multiculturalism has been seen as posing challenges to basic principles of Finnish welfare society: Individual rights are challenged by group rights (e. g. circumcision), equal treatment by equality of results and affirmative action, and the assumption of welfare society that people are basically similar by the assumption of multiculturalism that people have differences that should be recognized and accounted for (Puuronen 2004). Rhetoric on equality is also integral in Finnish populist political platforms. Sakki and Pettersson (2016) demonstrate how parliament members from the influential Perussuomalaiset ('The Finns Party') use Finnish equality to justify their racist stance on cultural diversity. 


\section{Methods}

\subsection{Data collection methods}

I used two sampling strategies in this study. Because we have little knowledge on value meanings among the majority in Finland, I firstly recruited people through a random sample obtained from the Finnish Population Register Centre. These people were contacted by letter through the post. Two hundred and forty people from the random sample participated (ages 16 to 70, 154 female, 86 male). Secondly, I wanted to invite people whose "ways of being" have been defined as abnormal and therefore positioned in the margins by social structures - people who may conceptualize and position equality differently than the majority. I also recruited people with transgendered life experiences ( $N=40$, ages 17 to 46, 9 female/MtF, 15 male/FtM, 16 transgender) and people diagnosed with Asperger's syndrome ( $N=24$, ages 16 to 48, 15 female, 8 male, 1 transman). Respondents with transgendered life experiences are classified here according to how they described their sex/gender in a background question: F/MtF designates those labelled male at birth and who self-categorized as female or transwoman; M/FtM designates those labelled female at birth and who self-categorized as male, transman or transmasculine; TG designates those who self-categorized as transgender or gender neutral. Asperger's diagnosed respondents were also identified in background questions. Two people that responded as Asperger's diagnosed respondents also described themselves as having transgendered life experiences. One of them self-categorized as female and the other as transman. These respondents were solicited through local transgender and autism organizations, support groups and online discussion forums.

How do the ways in which these respondents' sex/gender embodiments and sociabilities are labelled by institutions - as diagnosable psychiatric "disorders" align with my perspective on identity? I take these institutional labels as reified identity categories that are imposed upon individuals, which both reflect and strengthen exclusionary norms related to sex/gender and sociability. They are also deficient identity categories, i. e. one among many that are available to these respondents while constructing and positioning values.

I chose to use an open questionnaire method for several reasons. I wanted to use a nationwide random sample and also wanted respondents with Asperger's diagnoses and/or transgender experiences to be located in as geographically diverse regions as possible. Meeting hundreds of respondents nationwide would 
have been impossible. I also thought that respondents with Asperger's diagnoses and/or transgendered experiences may consider themselves as being in sensitive positions, and consequently may find the method of writing written responses to open questions more comfortable than others that I considered. Lastly, I wanted all respondents to be able to respond anonymously.

The study was framed as dealing with how Finnish people conceptualize Finnish social structures and society, and themselves and others in society. Respondents, who gave informed consent, were instructed that their responses would be handled confidentially and that they would not be identifiable in any published articles or reports. I collected data by asking participants to write responses to eight open questions. The open questions were given and responded to in Finnish and then translated into English. I developed the questions with the intention of indirectly exploring value meanings, how they are constructed through demarcations of difference and are used in constructions of identity.

Respondents were asked to write responses to the following questions in their own words, and to explain their answers: Are people basically the same or basically different?; What types of people and groups of people do you like and what types do you not like?; What are the advantages or disadvantages of minorities living in Finland (for example the Sami, Swedish-speaking Finns, homosexuals, Muslims)?; What are Roma beggars doing in Finland?; Please complete the following sentence in your own words: The social structure in Finland is...; Is the Finnish state fair?; Does everyone have equal opportunities to realize their goals?; Do you see yourself belonging to any social strata, classes, segments or other such groups? Thus some of the questions were very open, while others were provided as stimulus items. The topic of "Roma beggars” (Romanikerjäläiset) has been prominent in the public sphere. I used this term on the questionnaire as it is the primary term used in the Finnish media to refer to non-Finnish Roma populations in Finland.

\subsection{Methods of analysis}

I analyzed the material by first reading and coding the entirety of respondents' texts with respect to how they made classifications related to equality by marking boundaries between "us" and "them." By identifying patterns in the classifications I gained an understanding of the main representations and discourses on equality. The framework on resources of ENGAGEMENT and GRADUATION (Martin 2004; Martin and White 2005) provides excellent tools for attending to how speakers/writers interact with and position the classifications and 
representations in their own texts as well as previous utterances around the same issue; how they stand with or against them, and the rhetorical strategies they use to do so.

Resources of ENGAGEMENT are used to refer to other texts, align with and take distance from them, and to adopt a position in relation to the content of communication and the putative audience (Martin and White 2005: 92-135). ENGAGEMENT resources include disclaim, proclaim, entertain and attribute. Disclaim can be used to negate, deny, reject or counter alternative viewpoints (e. g. although the decision was lawful, it is not fair). Instances of proclaim work to bring in close, endorse, or pronounce viewpoints as valid or reliable (e. g. of course, someone will be left out). Entertain is a means for conveying that the viewpoint is one among others. Entertain resources include expressions of likelihood through the use of epistemic modalities (e.g. a peaceful solution is possible), mental verb projections and evidence-based utterances (e.g. I think, $\overline{\overline{I \text { doubt }}}$, and deontic modalities (e.g. you should report your results). The speaker/writer can attribute viewpoints to others by reporting their speech or thought (e. g. they believe that the decision is fair). GRADUATION resources are used to scale viewpoints according to focus or force (Martin and White 2005: 135-159). Graduations of focus sharpen or soften categories that are typically either/or (e. g. they live in a true democracy). Graduations of force scale viewpoints by qualifying the intensity - for example, of the quality (e.g. they performed brilliantly) or process (e.g. it terrified me) - or the quantity with respect to amount or extent (e. g. wide-spread discrimination).

In each excerpt that I analyze, relevant instances of ENGAGEMENT and GRADUATION are marked as in the examples above (see also the appendix).

\section{Empirical analyses}

When considering the patterned classifications (representations) in the entire corpus of texts, respondents constructed two dominant discourses on equality. I have named these equal sociability and equality contracts. These two discourses were articulated to greater and lesser extents by respondents recruited through both of the sampling strategies. There are also two marginal discourses, which I refer to as equality as sameness and equality with differences. Equality as sameness was rarely constructed by respondents with an Asperger's diagnosis and/or transgendered experiences. Conversely, equality with differences was articulated primarily by respondents with an Asperger's diagnosis and/or transgendered experiences. My identifying and naming these dominant and marginal 
discourses was the culmination of my emic examination of us/them classifications and representations on equality.

In Sections 3.1-3.4, I briefly outline the salient "us" and "them" classifications in each of the four discourses. My focus in these sections is on close readings of how respondents position those classifications using ENGAGEMENT and GRADUATION resources.

\subsection{Doing equal sociability}

In the discourse on equal sociability, respondents represent equality by drawing boundaries around "us" in terms of non-hierarchical sociability and social solidarity. In doing the discourse on equal sociability, respondents position all individuals on the same psychological level, where "we" are not above others. Closed-minded viewpoints and struggles for personal distinction are disaligned and seen as incompatible with "our" identities and social practices. Respondents perform this discourse by taking up representations on equality that are built upon two interrelated themes: moderation and togetherness.

Firstly, then, respondents represent equal sociability through "us" classifications of the moderate, ordinary, average, realistic, authentic and genuine, and through negatively evaluated "them" classifications of the rich, greedy, elite, arrogant, posing, superficial, artificial, empty, extreme, fanatical and noisy. They align with these classifications, doing equal sociability by articulating "we" identities of moderation into storylines of equal, like-minded people who are ordinary and average, have goals that are not "too lofty" and beliefs that are not fanatical. Excerpt (1) is a good example of how respondents perform discourses on equal sociability in terms of moderation. The text was produced by a respondent from the random sample.

(1) Respondent199, Female

Variety is enriching. Different groups bring out variety more strongly in Finnish society. Variety becomes a problem if it's brought out very strongly or a minority group makes a lot of noise about themselves, demanding significant extra rights $\forall$. the so-called normal population.

Although the respondent begins in Excerpt (1) by positively evaluating "variety", her text quickly shifts to problematizing excess. Non-ordinary and immoderate viewpoints are attributed to different groups: those with "very strong variety", "noisy minorities" and those who "demand significant extra rights". The respondent disclaims these viewpoints, distancing them from "normal populations". 
"So-called" could be used to entertain alternatives to the viewpoints of the normal population, thus tempering the binary between problematic variety and extra rights on the one hand, and "normality" on the other. Yet in this excerpt the respondent uses this resource to "manage" the identification and "save face" (see e. g. Van Dijk 1992). Thus, here, entertain works to counter any reader expectations of the respondent's intolerance to anything that is "not normal." Consequently, "so-called" does little in decreasing the distance between excess and normality. Multiple instances of graduation work to downscale the force of variety and upscale the force of ordinariness and moderation. In Excerpt (1) the respondent maps storylines of "excess rights" and self-elevation onto the identities of "loud and demanding minorities", while somewhat implicitly positioning the "normal population" into storylines of moderation and balance.

Equal sociability was also constructed as respondents adopted positions on moderation in terms of having "properly proportioned" goals. This way of aligning with moderation is demonstrated in Excerpt (2), which was also written by a respondent from the random sample.

R194, M

In principle, yes [everyone has equal opportunities to realize their goals],

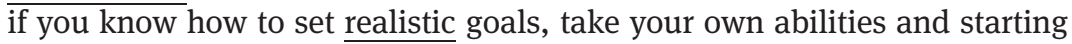
points into consideration. Not everybody's “goals” deserve any opportunities in society at all when looking at the big picture.

In Excerpt (2), the respondent adopts a position of tempered goal-setting. He uses the phrase "in principle" to both proclaim the existence of equal opportunities as well as to entertain other positions and qualify his own. This engagement works together with subsequent instances of disclaim and intensifications of force to align equal opportunities with the viewpoints of the "realistic" and those who "look at the big picture". The respondent positions equal opportunities as being available for realization within somewhat essentialized boundaries of "ability" and class. Those who have "realistic goals", do not stray from their social position or aim too high are aligned with storylines of "deserving” equal opportunities. The two excerpts analyzed thus far are good examples of how equality can be used in positioning to legitimate power-imbalanced cultural identities.

Secondly, respondents represent equal sociability in relation to togetherness by compartmentalizing the territory of "us" through classifications of openmindedness, tolerance, acceptance, respect, empathy, honesty, balance, diversity and enrichment. The moral orders of "them" are drawn around narrowminded, disruptive and violent people, interference, conflict, discrimination, categorization, and those who subjugate others. In doing equal sociability in 
relation to "togetherness" and social solidarity, respondents position storylines of equality-minded people who are or should be open, tolerant and cooperative onto “our” identities. They align psychosocial like-mindedness and harmonious interpersonal relations with egalitarian social relations. This way of doing equal sociability is demonstrated in Excerpt (3), which was articulated by a randomly sampled respondent. She puts forth a position on togetherness by aligning with elements related to non-interference and non-categorization.

\section{(3) R197, F}

I don'` see any more harm than benefit [in various minorities]. If a person lives a balanced life without disturbing or trying to affect other people's lives, I wouldn't categorize anyone. There are people from Savo, Ostrobothnian people, Karelian people and people from Helsinki, not to

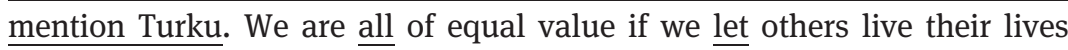
without meddling in their affairs.

In the first half of the text the respondent aligns with balance firstly by disclaiming distinctions, disturbance and interference. She uses these instances of disclaim together with attribute and entertain to position herself into storylines of non-categorization, equal human worth, balance and non-interference. The respondent also classifies and lists people according to different geographic regions in Finland. This establishes equivalencies between people from different areas in Finland, as well as works together with a maximization to upscale the force of the equal worth of "all" people. While in Excerpt (3) the respondent performed equality by juxtaposing it with distinctions and interference, in other texts respondents aligned differences with conflict and positioned them onto the identities of "them." In those texts, minorities are often importers of problems and thus excluded from the possibility of taking up positions on "togetherness." I will return to Excerpt (3) in a subsequent section.

\subsection{Doing equality contracts}

In the discourse on equality contracts, respondents represent equality by territorializing "our" equality in terms of the distribution of rights and resources on the one hand, and individual responsibilities to contribute to the common good on the other. Respondents use the discourse on equality contracts to take up positions on universalism and communalism. When positioning universalism, they construct a Finnish social identity by aligning and disaligning with the idea that Finnish equality is the "same for everybody". 
Representations of equality contracts are therefore firstly constructed as respondents draw the boundaries of "us" in relation to "the same for everybody" in laws and rights, education, social services and resources, voice and participation, and social class. Equality contracts as the same for everybody is also compartmentalized through negatively evaluated "them" classifications of inadequate material resources and social services, economic class distinctions and social divisions, the state and its representatives, uneven application of the law, politicians and the elite, and "globalization" or the influence of "nonFinnish" market factors. When respondents take up positions that are in high solidarity with the concept that equality is "the same for everybody", they classify and represent equality through broad viewpoints such as "everybody", "we", "society" and "Finland". They consider equality an aspect of civil life that is an existing and available resource. It is codified and guaranteed by law, national health care and education systems. Intensifications of equality as widely and evenly distributed are typical here.

Excerpt (4) was produced by a respondent from the random sample. It exemplifies how respondents formulate equality contracts by aligning with the "truth" of the universal distribution of Finnish rights and resources.

(4) R116, F

[The structure of society in Finland is] one of the most equal in the world. All people in Finland have the right to go to school. That is guided by laws of Finland. The comprehensive school guarantees a good beginning for everyone. Then you can continue in different types of schools. [...] It is the comprehensive school that gives the same facilities for everyone. It is free. From there, you can go on to upper secondary school, the university and graduate to the profession you want. For studying you get a study grant and a loan. Also for example there are schools for the disabled where they are taught and they can get the same types of positions. Money is no object if you want to advance. [...]

In Excerpt (4), the respondent proclaims schooling as a "right [...] guided by laws" that provides "guarantees". These instances of proclaim work to align equality, universalism and Finland. Using resources of entertain, the respondent positions everyone into storylines of possibilities for higher education and a chosen profession. The respondent upscales the force of equality contracts through multiple intensifications and quantifications. Discursively extending the benefits of equality to "the disabled" further maximizes the abundance of equality. This intensifies equality as an extensive Finnish resource that is available even to those who may face greater challenges. An instance of disclaim at 
the end of Excerpt (4) works to disalign the respondent with alternative viewpoints on equality that implicate uneven material resources, while simultaneously entertaining individual will. This brings elements of individual effort and achievement into equality. Finnish equality becomes simply taking what is available for all, further positioning it as an ontological truth.

Equality contracts as the same for everybody was also performed in low solidarity with the classification system. Here, "our" equal laws and rights, education, social services and resources, voice and participation are positioned as under threat, an illusion or untrue. Finnish society is positioned into storylines of increasing economic and social divisions, and a faltering social services sector. As with all of the texts analyzed thus far, Excerpt (5) was written by a randomly sampled respondent.

R127, F

[The social structure in Finland] has changed in my view since the depression of the 1990s. The division into the poor and the rich seems to be widening. The basic health care, care for the elderly and social security have become significantly worse. [...] Although for example comprehensive school is free and there are ne term fees for higher education yet, but it's pretty impossible for an unemployed person or a single parent to get an education for their children in another town.

In the first half of Excerpt (5) there are two instances of entertain, which are epistemic modalizations that work to signal uncertainty in the respondent's position on inequality. Overall in this study, disaligning performances of "the same for everybody" are uttered with less certainty than are aligning performances. Entertain and disclaim work together in the second half of the excerpt to disalign with the viewpoint that free education ensures equal opportunities. This points to the taken-for-granted status of Finnish equality, as something assumed to exist inside the nation. As an inherent aspect of the social structure, actors contending with its assumed status must both take up and oppose deeply embedded "truths". The respondent uses graduations of force in aligning the social structure with fading equality. This positioning is accomplished through non-universal viewpoints of somewhat isolated individuals - the respondent, those in need of social support, the unemployed and single parents.

Secondly, equality contracts is performed in relation to communalism and societal responsibilities. Here, respondents construct a Finnish social identity by positioning the building and maintenance of equality contracts as a common obligation that demands the "same from everybody". The boundaries of the "proper citizen" are drawn around those perceived as hard-working, 
independent, tax-paying contributors to the common good. "Them" categorizations include self-interest, laziness, dependency, loafers, and receiving or abusing social services.

This way of doing equality contracts is demonstrated in Excerpt (6), which comes from a respondent from the random sample.

(6) R109, M

I like people who are conscientious in their work and work hard for everybody's future and don'€ just think about themselves, accusing others and defending their laziness, i. e. I don’ł like lazy people.

In Excerpt (6), the respondent takes up a position on communalism by attributing viewpoints of conscientiousness of the common good through hard work to "desirable people", and by upscaling the force of responsibilities to contribute to "everybody's" future. He uses disclaim and attribute to disalign with the selfish, confrontational and lazy perspectives of "them". The respondent takes up a position using discourses on equality contracts by aligning storylines of equal contribution to the common good with the identities of the "good citizen”.

\subsection{Doing equality as sameness}

The discourse on equality as sameness relies on a tension between obedience to a moral majority and deviance. Here, respondents represent equality by using elements from the two dominant discourses presented above, incorporating and emphasizing elements related to sameness and the nation, and bracketing out differences in social and cultural practices. Important classifications linked to "us" are sameness, naturalness and normalness, assimilation, conformity and tradition, authenticity and the nation. These classifications are positioned in opposition to "them" classifications such as immigrants, foreigners, minorities and difference. The project on equality as sameness is thus impeded by Others, which can include any group, person or thing considered antithetical to a cohesive nation, as well as "non-traditional" values, "distinctions" and "special services" for immigrants and minorities. All sorts of things that are perceived as being different from "Finnishness" are expelled outside of the cultural and moral boundaries of "us", while representations of Finnishness and equality encompass elements of sameness.

In doing the discourse on equality as sameness, respondents construct a national identity by aligning with Finnish equality, original Finnishness and 
continuity of tradition. They perform equality values by positioning "us Finns" into storylines of upholding equality. The identity of Others and their perceived social and cultural differences are articulated into storylines of inequality and oppression. Excerpt (7) demonstrates how a randomly sampled respondent draws from this discourse to represent and align with Finnish equality.

\section{(7) R136, F}

I consider all groups of people of equal value. [...] I think people are

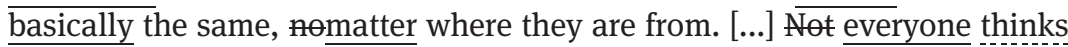
in the same way as me. I don't like people who entitle themselves to act differently than [what] my morality is. For example, in some cultures a woman's status is weak and I don't understand that. I would n't want to be treated like that. I'm happy that I was born a Finn. Even though I try to see the good in everyone, I can't help that I am almost racist when I think about the rights of women and children.

The respondent constructs personal and national(ist) identities by positioning equality, sameness, difference, and individuals that she perceives are connected to those classifications. She uses entertainment resources to both align with a "Finnish viewpoint" on equality and to leave room for other viewpoints. Instances of disclaim and attribute work together with negatively evaluated classifications of difference to implicate a value in "moral sameness". Subordinating behavior toward women is attributed to some non-Finnish cultures and disclaimed from her and Finns' moral viewpoints on Finnish gender equality. "Even though [...] I can’t help that" signals the respondent entertaining and disclaiming discourses on tolerance that are external to the text. This works to position unbridled positive recognition of cultural differences as problematic to those such as the respondent, who entertain, uphold and proclaim equal rights for women and children.

Respondents sometimes accomplish equality as sameness by building the nation as homogenous and coherent, or previously that way, while multiculturalism is often understood as something exogenous that Finns face from the outside (cf. Tuori 2007). In reference to this I would like to return to Excerpt (3), which moves between equal sociability and equality as sameness. It is an example of how respondents can take up positions on "togetherness" to build a homogenous, nationalist identity that uses equality to bracket out differences. The categorization of people according to geographic region works to establish equivalencies between people from different parts of Finland and minority groups such as those that are given as examples in the question. This way of listing "Finnish minorities" semantically subverts existing differences (see 
Fairclough 2003: 88-103). It asserts the "equal value" of differently valued groups of people, claims minority experiences as universal and equivalent, and conceals the unequal positions of Others in Finnish culture (cf. Ahmed 2000: 173).

Equality as sameness was articulated primarily by random sample respondents. Yet individuals that are subordinated by institutionalized norms may also construct colonizing values and identifications on equality. The following excerpt was written by a respondent with transgendered experiences.

(8) R59, TG

[...] Diversity increases the atmosphere where everyone is allowed to make personal choices in life, so from this perspective minorities are beneficial in general. On the other hand this applies only to minorities that don't actively strive to decrease other people's freedom of expressing themselves. Different religious groups, such as Muslims, are disadvantageous. Particularly immigrants from countries with different values than Finland's values can perhaps be disadvantageous to society, because an increase in misogyny and homophobia do not increase the well-being of the people. [...]

In Excerpt (8), the respondent entertains the viewpoint that minorities contribute to diversity, and thus to an open and free environment for "everyone". Minorities are thus of instrumental value to the project on freedom. The respondent uses disclaim and focus to align with "favorable Finnish national minorities" who are believed to contribute to everyone's freedom. Oppression and inequality (misogyny, homophobia) are attributed to the viewpoints of Muslims and immigrants with non-Finnish values, while their contribution to well-being is disclaimed. This excludes them from viewpoints of "favorable Finnish minorities". "Can perhaps" is an instance of entertain, which is used by the respondent in an attempt to rhetorically soften the polarized position. Finnish equality, freedom and religious and cultural traditions are nevertheless used to construct identities of "favorable Finnish national minorities".

\subsection{Re-doing equality with differences}

Lastly, respondents construct the discourse on equality with differences in opposition to aspects of the other discourses presented and analyzed in this paper. In this discourse, emphases on moderation and ordinariness, non-conflict, equality as an existing reality, normativity and continuity of tradition are problematized. 
Respondents represent equality by drawing the boundaries of "us" around social inclusion, difference, equal rights, equal human worth, and equal voice and participation. Equality values are constructed as envisioned, rather than as available, accessible truths. Equality is built in opposition to negatively evaluated "them" classifications in the "now social order" such as conformism and norms, society and the social order, exclusion, lack of resources, and narrowmindedness.

In doing the discourse on equality with differences, respondents therefore represent equality by constructing and aligning with viewpoints that account for differences. They position difference as being cast out of Finnish equality in the "now social order". They identify with an envisioned equality by opposing "Finnish equality" that is built with classifications of conformity and social exclusion. Their envisioned equality accommodates difference by proclaiming it as inevitable and aligning it with equality, innovation and societal wellbeing.

The following excerpt demonstrates how respondents perform this discourse by disaligning with the omnipresent norms and social structures that they believe are primary obstacles for realizing equality. Although it was written by an Asperger's diagnosed respondent, respondents with transgendered experiences also often implemented Finnish equality by disaligning with classifications and storylines on exclusionary norms.

\section{(9) R23, M}

No [everyone does not have equal opportunities]. For example, our education system is only suitable for a certain type of learner. Different people are not tolerated, the idea is to get everyone to fit the same mold.

In Excerpt (9), the respondent represents equality by disaligning with a discourse on equality contracts that suggests that the education system ensures equality in Finland. Focus resources are used to narrow the distribution of Finnish equality to include "only [...] certain types”. Using disclaim and entertain, the respondent also positions the exclusion of differences in opposition to equal opportunities. Entertain appears as deontic modalizations, constructing a societal coercion to "fit the same mold". The respondent intensifies the force of intolerance of difference with this metaphorical classification of conformity and its maximal distribution to "everyone".

The last excerpt that I analyze demonstrates an important and distinguishing aspect of this identification; respondents position the implementation of differences as necessary for the realization of equality. It was produced by a respondent with transgendered life experiences and an Asperger's diagnosis. 
(10) R9, F

[....] Different minorities are [...] the building blocks of Finnishness, just as bricks are the building blocks of a house. The house will be ruined if its building blocks start to be arbitrarily demolished. Likewise, Finnishness becomes impoverished and shrinks if its minorities are forcibly oppressed. Different types of groups of people possess different types of information. Using the information would make life happier and easier and would address the value of the groups.

In Excerpt (10), the respondent uses numerous metaphors and intensifications to upscale the force of minorities' foundational positioning in Finnishness. Toward the end of the excerpt different types of information are attributed to different types of groups of people, whose non-subjugation is foundational for the health of Finnishness. Three instances of entertain work in implicating that different groups' information and value have remained unaccounted for. The respondent aligns "us" with minorities, cultural diversity, difference, non-oppression and human worth, and holders of valuable information.

\section{Discussion and conclusion}

The close readings of respondents' uses of ENGAGEMENT and GRADUATION resources indicate how representations and implementations of equality occur in concrete constructions of identity. This study thus makes a methodological contribution by demonstrating specific tools that can be utilized in research on social values. On an empirical level my analyses show the different ways that Finnish citizens represent equality, and how they use those meanings to construct identities and stratify the social sphere. The analyses suggest that elements of seemingly benign but taken for granted forms of equality can be taken up and performed in subjugating and socially exclusive ways. Some respondents also disclaim dominating discourses on equality that they may find themselves excluded by. Whether subjugating or oppositional, representations and alignments with values always occur in relation to previous utterances, viewpoints and discourses around the same issues. What we know about the historical path of equality is represented in all of the discourses analyzed in this paper.

Equal sociability is a social normative discourse, showing close ties to the equality and temperance values of rural traditions. Psychologically placing oneself above others is arguably incompatible with egalitarian sociability. However, this discourse is sometimes used such that distinctions are shunned. 
Storylines on moderation include negatively evaluated classifications, such as having "lofty" goals and standing out, that are pushed outside of the boundaries of Finnish equality-mindedness. Alignments with storylines on "togetherness" can also begin a process of purging Others. This occurs when differently socially positioned groups are discursively made equivalent, non-interference is aligned with equality, and minorities are aligned with difference and conflict. My analysis of equal sociability resonates with Van Leeuwen's (2005 : 56) discussion of conformity in "egalitarian" societies. Those who do things differently are often perceived as placing themselves above others, potentially leading to suspicions against them and social exclusion.

The discourse on equality contracts is used to construct an identity for the Finnish "egalitarian order". This discourse reflects movement of equality values through various formalization processes such as suffrage, government initiatives aimed at dissolving class distinctions, and the building of the welfare state. There are arguably both benefits and drawbacks to strictly defined policies that offer the same resources to everybody. However, I would like to emphasize that in this discourse alignments with "the same for everybody" are often accomplished by disclaiming the existence of social classes, proclaiming the "truth" of equality by referencing "available" resources of the welfare state, or validating Finnish equality by making international comparisons. There is an obvious danger in legitimating or denying as objective entities the existence of social classes. These performances of equality fail to acknowledge that equality as a social good is not simply available to all parts of the population, awaiting retrieval or to be claimed through effort. Such ways of doing equality, sameness and difference uphold relations of domination by ignoring that some are actually "more equal" than others in their abilities to access and make use of various public goods and social services, employment and educational opportunities. Accordingly, these performances are in denial of some having less means or opportunities for contributing to the common good.

Equality as sameness and equality with differences are marginal, polemic discourses. They are built around an ideological struggle related to the roles that sociocultural sameness, difference and Finnishness occupy in representing and aligning with equality. These competing discourses are formulated by including and renegotiating elements from the other discourses in specific ways. They reflect interpretations of changes occurring in Finnish society. Material inequalities have become more pronounced with the dismantling of the welfare state. Migration and transnationalism have contributed to increased heterogeneity in the population and culture.

Equality as sameness is a backlash against these changes. This discourse is accomplished by sharpening boundaries and by shifting from valuing non- 
distinctions to obligating them. The examination makes obvious the dangers in disclaiming differences and positioning them as a threat to equality. It clarifies how graduations of language are used to reinforce ordinariness and moderation in equality, and equivalencies in the worth of people who are differently valued. This way of doing equality is common in the rhetoric of Perussuomalaiset, who now occupy the second highest number of seats in parliament. Their political platform combines support for the welfare state and working classes with conservative, right-wing values. The party evolved out of the Agrarian League of 1906. It therefore has direct historical links to Finnish peasant and rural class cultures. Respondents putting forth positions on equality as sameness demonstrate how equality can be a technology for performing exclusion and stratifying the social sphere.

In re-doing equality with differences there is an interest in exposing the difficulties for some in accessing Finnish equality. The analysis suggests that some have started to deconstruct an equality that obligates conformity with dominant social and cultural practices. The envisioned equality in this discourse is aligned with accounting of and clearing space for social and cultural differences. The close readings demonstrate some of the ways that exclusionary discourses can be drawn upon and done differently by individuals interested in renovating equality. Unlike the other discourses analyzed in this study, equality with differences was formulated primarily by respondents with Asperger's diagnoses and/or transgendered experiences.

My analyses suggest that social position can - depending at least in part on topic as well as both situational and sociocultural context - have an effect upon how particular social values are formulated and used in identification. In this study, this effect seems to be in part due to the hegemonic status of equality as a social value, to the homogenizing elements that have been gathered along its historical path to give it meaning, and to the implementation of equality in national identification and enforcing of Finnishness. Some forms of equality have been updated in alignment with moderation and sameness, and inherent Finnishness. The elevated position and homogenizing meanings of Finnish equality make it an easily accessible tool for stratifying the social sphere. This also makes it a target of contestation. It is important to not only expose exclusionary tendencies in Finnish equality discourses, but also to emphasize how they are being actively opposed. Dominant discourses, representations, and social and cultural identities on equality are susceptible to transformation when other important constituting elements are repositioned. Subjugating forms of equality are therefore already being transformed at the level of everyday communication. In redoing equality with differences, space is cleared for the implementation of differences in Finnish equality. 
The study elaborates a distinction between aligning instrumentally with differences for imposing the old, and practicing difference in interaction with the new; between recognizing differences and grasping them, and between tolerating differences and considering the totality of the Other. When difference is constructed as something of instrumental value there is the danger that it will be recognized yet subsumed into dominant cultural identities, serving to expand imperialist meanings and to entertain the "taste" of hegemonic culture; "that the Other will be eaten, consumed, and forgotten” (hooks 1992: 39). In many of the discourses analyzed in this paper, individuals articulate a value in diversity when producing equality. Yet they build storylines such that the totality of the Other is broken apart and picked through. Using difference instrumentally, fragmenting the totality of the Other and swallowing only that which is familiar or easily understood contributes to a hegemonic sameness, to a tightly bordered and exclusive "equality" that espouses an obligation to act in accordance with hegemonic practices. Similar to research on "New Racism" (e. g. Fozdar 2010), my analyses show how discourses on equality are taken up and used to legitimate social and cultural inequalities.

Equality is a central value not only in Finland but in many linguistic, social, cultural and institutional contexts. It is worth examining the semantics and uses of equality and other values that are often normative - such as tolerance, democracy and freedom. Life experiences can affect how particular values and discourses are constructed and used in identification. Yet social classes and structural relations of domination do not simply determine viewpoints, values and discourses. We saw that individuals who have been labelled in subjugating ways - who have been ascribed "dysfunctional identities" - can also negotiate exclusionary identifications.

Every use of language is linked to the social locations of those who produce the utterances, is motivated and involves ideological change (Voloshinov 1986: 94). In contemporary social spheres these social locations are complex and dynamic. Identities are unstable and shifting. Future research on how audiences thought to be in different social locations receive and reproduce hegemonic and counter discourses could further contribute to understanding these complexities. It could contribute to knowledge on how discourses are mediated and transformed in each reception, disarticulation, representation and positioning of values in identification.

Acknowledgments: This paper was written as part of my doctoral study funded by the Kone Foundation, a Finnish Doctoral Program in Social Sciences (SOVAKO) and the Doctoral Program in Social Sciences at the University of Helsinki. I want to thank Jukka Törrönen, Satu Venäläinen and three anonymous reviewers for their critical and constructive comments. 


\section{Appendix Coding conventions}

Instances of respondents' uses of ENGAGEMENT and GRADUATION resources in the example texts are marked as follows:

\begin{tabular}{|c|c|}
\hline strikethrough & indicates instances of disclaim \\
\hline bold text & indicates instances of proclaim \\
\hline double underlining & indicates instances of entertain \\
\hline$\overline{\text { dashed underlining }}$ & indicates instances of attribute \\
\hline single underlining & indicates instances of graduations of focus and force \\
\hline
\end{tabular}

\section{References}

Ahmed, Sara. 2000. Strange encounters: Embodied others in post-coloniality. London: Routledge.

Alasuutari, Pertti. 1991. Individualism, self-Control, and the Finnish temperance movement. Ethnos 56(3-4). 173-188.

Bakhtin, Mikhail. 1981. The dialogic imagination. Austin: University of Texas Press.

Davies, Bronwyn \& Rom Harré. 1990. Positioning: The discursive production of selves. Journal for the Theory of Social Behaviour 20(1). 43-63.

Esping-Andersen, Gøsta. 1990. The three worlds of welfare capitalism. Cambridge: Polity Press.

Fairclough, Norman. 2003. Analysing discourse: Textual analysis for social research. London: Routledge.

Fairclough, Isabela \& Norman Fairclough. 2012. Political discourse analysis. Oxon: Routledge.

Fozdar, Farida. 2010. Duelling discourses, shared weapons: rhetorical techniques used to challenge racist arguments. Discourse and Society 19(4). 529-547.

Granberg, Leo \& Jouko Nikula. 1995. Introduction. In Leo Granberg \& Jouko Nikula (eds.), The peasant state: The state and rural questions in 20th century Finland, 7-19. Rovaniemi: University of Lapland.

Häkkinen, Antti \& Miika Tervonen. 2004. Ethnicity, marginalization and poverty in the 20th century Finland. In Vesa Puuronen, Antti Häkkinen, Anu Pylkkänen, Tom Sandlund \& Reetta Toivanen (eds.), New challenges for the welfare society, 22-39. Joensuu: Joensuun yliopisto.

Häkli, Jouni. 1999. Cultures of demarcation: territory and national identity in Finland. In Guntram H. Herb \& David H. Kaplan (eds.), Nested identities: Identity, territory, and scale, 123-150. Lanham: Rowman \& Littlefield.

Hall, Stuart. 1990. Cultural identity and diaspora. In Jonathan Rutherford (ed.), Identity: Community, culture, difference, 222-237. London: Lawrence and Wishart.

Holli, Anne Maria. 2003. Discourse and politics for gender equality in late twentieth century Finland. Helsinki: Acta Politica.

hooks, bell. 1992. Black looks: Race and representation. Boston: South End Press. 
Julkunen, Raija. 2002. Timanttejakin parempi ystävä? Hyvinvointivaltion murroksen sukupuolittuneet seuraukset [Better friend that diamonds? The gendered consequences of the changes in the welfare state]. In Anne Maria Holli, Terhi Saarikoski \& Elina Sana (eds.), Tasa-arvopolitiikan haasteet [The challenges of gender equality politics], 32-49. Helsinki: WSOY.

Kuusi, Pekka. 1964. Social policy for the sixties. A plan for Finland. Helsinki: Finnish Policy Association.

Lempiäinen, Kirsti. 2002. Kansallisuuden tekeminen ja toisto [The making and repetition of nationality]. In Tuula Gordon, Katri Komulainen \& Kirsti Lempiäinen (eds.), Suomineitonen, hei! Kansallisuuden sukupuoli [Miss Finland, hey! The gender of nationality], 19-36. Tampere: Vastapaino.

Mäkelä, Klaus. 1985. Kulttuurisen muuntelun yhteiskunnallinen rakenne Suomessa [The social structure of cultural variation in Finland]. Sosiologia 22 (4). 247-260.

Martin, James R. 2004. Mourning: how we get aligned. Discourse \& Society 15(2-3). 321-344.

Martin, James R. \& Peter R. R. White. 2005. The language of evaluation. Hampshire: Palgrave Macmillan.

Menard, Rusten. 2016. Analysing social values in identification; a framework for research on the representation and implementation of values. Journal for the Theory of Social Behaviour 46. 122-142. doi: 10.1111/jtsb.12087.

Paasi, Anssi. 1992. The construction of socio-spatial consciousness. Geographical perspectives on the history and contexts of Finnish nationalism. Nordisk Samhällsgeografisk Tidskrift 15. $79-100$.

Puuronen, Vesa. 2004. The Finnish welfare society at the beginning of the $3^{\text {rd }}$ millennium. In Vesa Puuronen, Antti Häkkinen, Anu Pylkkänen, Tom Sandlund \& Reetta Toivanen (eds.), New challenges for the welfare society, 7-21. Joensuu: Joensuun yliopisto.

Räsänen, Riitta. 1989. Kotiseutuaate ja kotiseutuliike suomalaiskansallisessa prosessissa [The idea of the homeland and homeland movement in processes of Finnish nationalism]. In Teppo Korhonen \& Matti Räsänen (eds.), Kansa kuvastimessa. Etnisyys ja identiteetti [Citizens in a mirror. Ethnicity and identity], 10-28. Helsinki: Suomalaisen Kirjallisuuden Seura.

Sakki, Inari \& Katarina Pettersson. 2016. Discursive constructions of otherness in populist radical right political blogs. European Journal of Social Psychology 46. 156-170. doi: 10.1002/ejsp.2142.

Sowińska, Agnieszka. 2013. A critical discourse approach to the analysis of values in political discourse: The example of freedom in President Bush's State of the Union addresses (2001-2008). Discourse \& Society 24(6). 792-809.

Sulkunen, Irma \& Risto Alapuro. 1987. Raittiusliike ja työväestön järjestäytyminen [The temerance movement and the organisation of the working class]. In Risto Alapuro, Ilkka Liikanen, Kerstin Smeds \& Henrik Stenius (eds.), Kansa liikkeessä [Nation on the move], 142-156. Helsinki: Kirjayhtymä.

Törrönen, Jukka. 2014. Situational, cultural and societal identities: Analysing subject positions as classifications, participant roles, viewpoints and interactive positions. Journal for the Theory of Social Behaviour 44(1). 80-98.

Tsirogianni, Stavroula \& Gordon Sammut. 2014. Transitivity analysis: A framework for the study of social values in the context of points of view. British Journal of Social Psychology 53(3). 541-556. 
Tuori, Salla. 2007. Cooking nation: Gender equality and multiculturalism as nation-building discourses. European Journal of Women's Studies 14(1). 21-35.

Van Dijk, Teun A. 1992. Discourse and the denial of racism. Discourse \& Society 3. 87-118. Van Leeuwen, Theo. 2005. Introducing social semiotics: An introductory textbook. London: Routledge.

Voloshinov, Valentin Nikólaievich. 1986. Marxism and the Philosophy of Language. London, England: Harvard University Press.

\section{Bionote}

\section{Rusten Menard}

Rusten Menard is a doctoral student in the Department of Social Research at the University of Helsinki, Finland. His research interests include social values, positioning, identification, critical discourse analysis, social semiotics, qualitative and post-qualitative methodologies, and discourse and social transformation. 